\title{
Enhancement of Responding to A After A+/AX+ Training: Challenges for a Comparator Theory of Learning
}

\author{
Guillem R. Esber and John M. Pearce \\ Cardiff University
}

\author{
Mark Haselgrove \\ University of Nottingham
}

\begin{abstract}
Two appetitive Pavlovian conditioning experiments with rats investigated the associative changes that A undergoes in an $\mathrm{A}+/ \mathrm{AX}+$ blocking procedure. Conditioned responding to $\mathrm{A}$ was enhanced relative to stimulus $\mathrm{B}$, which had been conditioned in isolation $(\mathrm{B}+)$. This result was interpreted in terms of the formation of a within-compound association between A and X. The results of Experiment 2 supported this conclusion by demonstrating that $\mathrm{X}$ had associative strength of its own and, furthermore, that extinguishing $\mathrm{X}$ resulted in a similar level of responding to $\mathrm{A}$ and $\mathrm{B}$. These results are considered in terms of retrospective revaluation theories of learning.
\end{abstract}

Keywords: conditioning, stimulus competition, blocking, within-compound association

The finding that stimuli will compete with one another to become associated with an outcome has generated much interest in the field of animal learning and conditioning. The seminal demonstration of this effect was provided in a fear conditioning experiment by Kamin $(1968,1969)$ in which rats in an experimental group, but not in a control group, were given paired presentations of a conditioned stimulus (CS), A, with a mild footshock (A+). In Stage 2, both groups then received trials in which a compound of $A$ and a new stimulus, $X$, was paired with shock $(A X+)$. In a final test session, $\mathrm{X}$ was presented by itself. Rats in the control group showed a considerable conditioned response to $\mathrm{X}$, whereas there was almost no evidence of conditioned responding to $\mathrm{X}$ in the experimental group. Since the publication of these influential articles, this so-called blocking effect has been demonstrated in a variety of species using a number of different conditioning procedures. For example, blocking has been demonstrated in rats using appetitive Pavlovian conditioning (Ganesan \& Pearce, 1988; Holland, 1984) and taste-aversion conditioning (Willner, 1978) and spatial learning (e.g., Pearce, Graham, Good, Jones, \& McGregor, 2006; Rodrigo, Chamizo, McLaren, \& Mackintosh, 1997). In addition, there is evidence of blocking in species as diverse as honeybees (e.g., Blaser, Couvillon, \& Bitterman, 2004), goldfish (Tennant \& Bitterman, 1975), and humans (Dickinson, Shanks, \& Evenden, 1984; Le Pelley, Oakeshott, \& McLaren, 2005).

In all of these experiments, the focus of investigation has been the conditioned properties, or lack thereof, that stimulus $\mathrm{X}$ acquires during the trials with $\mathrm{AX}$ in Stage 2 as a consequence of the preceding conditioning with $\mathrm{A}$ in Stage 1. What has received

Guillermo R. Esber and John M. Pearce, School of Psychology, Cardiff University, Cardiff, Wales; Mark Haselgrove, School of Psychology, University of Nottingham, Nottingham, England.

Guillermo R. Esber is now at Johns Hopkins University.

This work was supported by a grant from the Biotechnology and Biological Sciences Research Council of the United Kingdom.

Correspondence concerning this article should be addressed to Mark Haselgrove, School of Psychology, University of Nottingham, Nottingham NG7 2RD, United Kingdom. E-mail: mark.haselgrove@nottingham.ac.uk considerably less attention are the changes to A that might have taken place as a consequence of $\mathrm{AX}+$ training. This is especially surprising when one considers that different theories of animal learning make rather different predictions about the impact that adding $\mathrm{X}$ to $\mathrm{A}$ will have in Stage 2. According to the theory of learning proposed by Rescorla and Wagner (1972; Wagner \& Rescorla, 1972), conditioning to A in Stage 1 will result in the development of an association between $\mathrm{A}$ and the unconditioned stimulus (US) that, if sufficient training is given, will reach an asymptote equal to the total amount of conditioning that can be supported by the US $(\lambda)$. Adding $X$ to A in Stage 2, and pairing this compound with the US, should result in stimulus competition so that $\mathrm{X}$ acquires rather little, or no, association with the US and hence the associative strength of $\mathrm{AX}$ should, like A, equal $\lambda$. The implication is that the conditioned properties of $\mathrm{A}$ remain the same throughout this stage: Adding X to A should leave A with the same associative strength as a control stimulus, B, that is simply paired with the US throughout Stages 1 and 2 without the addition of X.

A rather different prediction about the outcome of adding $X$ to A can be derived from the proposals of Miller and his colleagues (Miller \& Matzel, 1988; Stout \& Miller, 2007). According to their comparator hypothesis account of conditioning, stimuli do not compete with one another for an association with the US. Instead, stimuli acquire the same associative strength irrespective of whether they are conditioned in isolation or in compound with another stimulus (cf. Hebb, 1949). Stout and Miller (2007, pp. 760-762) proposed that on trials in which a CS is paired with a US, the change in the association between these stimuli is given by Equation 1a:

$$
\Delta \mathrm{V}_{\mathrm{s} 1, \mathrm{~s} 2}=\mathrm{s} 1 * \mathrm{~s} 2 *\left(1-\mathrm{V}_{\mathrm{s} 1, \mathrm{~s} 2}\right)
$$

where $\Delta \mathrm{V}_{\mathrm{s} 1, \mathrm{~s} 2}$ is the increment in the association $\mathrm{V}_{\mathrm{s} 1, \mathrm{~s} 2}$ between the CS and the US and s1 and $\mathrm{s} 2$ are parameters that represent the salience of, respectively, the CS and the US. The values of these and all other parameters lie between 0 and 1 . On trials in which the CS is presented in the absence of the US, the change in the association between these stimuli is given by Equation 1b: 


$$
\Delta \mathrm{V}_{\mathrm{s} 1, \mathrm{~s} 2}=-\mathrm{k} 1 * \mathrm{~s} 1 * \mathrm{~V}_{\mathrm{s} 1, \mathrm{~s} 2}
$$

in which $\mathrm{k} 1$ is a learning rate parameter that applies to trials in which the US (or s2) is absent. Stimulus competition effects, according to this theory, occur because the strength of responding to a stimulus is not determined just by its associative strength. Instead, stimuli that accompany the target stimulus during training are assumed to take on the role of comparator stimuli during testing and modulate the strength of the response it elicits. To appreciate this influence, consider an overshadowing experiment in which AX signals food. Both stimuli will gain associative strength during compound conditioning according to Equation 1a, and the rate of acquisition will be the same as if either stimulus was alone paired with food. If A, the target stimulus, should now be presented by itself, it will excite a representation of food directly through its own association with the US and, indirectly through its association with $\mathrm{X}$, the comparator stimulus. The strength of the response to $\mathrm{A}$ is then given by the difference between the extent to which the representation of food is activated directly and indirectly. This principle is expressed formally by Equation 2. The strength of the response to the target stimulus, $R_{t}$, is determined by its own associative strength, $\mathrm{V}_{\mathrm{t} \text {,us }}$, less some function of the product of the strength of the association between the target and comparator stimulus, $\mathrm{V}_{\mathrm{t}, \mathrm{c}}$, and the strength of the association between the comparator stimulus and the US, $\mathrm{V}_{\mathrm{c}, \mathrm{us}}$,

$$
\mathrm{R}_{\mathrm{t}}=\mathrm{V}_{\mathrm{t}, \mathrm{us}}-\mathrm{k} 2 *\left(\mathrm{~V}_{\mathrm{t}, \mathrm{c}} * \mathrm{~V}_{\mathrm{c}, \mathrm{us}}\right)
$$

The comparator term within the parentheses is limited to 1 , and $\mathrm{k} 2$ is a parameter that determines the influence of the comparator term. The growth of associations between the elements of a compound is given by Equations $1 \mathrm{a}$ and $1 \mathrm{~b}$.

According to the foregoing equations, conditioning with $\mathrm{A}$ in Stage 1 of a blocking experiment will result in the formation of an association between A and the US, with A coming to elicit con- ditioned responding. Interestingly, introducing trials in which AX signals the US in Stage 2 is predicted to reduce responding to A relative to a control stimulus, $\mathrm{B}$, which is simply paired, in isolation, with the US. This is because the associations that form between $\mathrm{A}$ and $\mathrm{X}$, and between $\mathrm{X}$ and the US during Stage 2, will make $\mathrm{X}$ an effective comparator for $\mathrm{A}$ and hence reduce the strength of the response elicited by A. The left-hand panel of Figure 1 shows the output of a computer stimulation of the comparator hypothesis that is based on Equations 1a, 1b, and 2. The simulation used parameter values recommended by Stout and Miller (2007). Thus, the salience of A, B, X, and the US was 0.71, and the value of $\mathrm{k} 2$ was 0.90 . The role of the experimental context was not considered in these simulations, but it is considered in additional simulations reported in the General Discussion. There were 80 simulated trials for Stage 1 and 40 simulated trials for Stage 2. Following the initial conditioning of $\mathrm{A}$ and $\mathrm{B}$, in which conditioned responding to these stimuli reaches an asymptote equal to 1 , introducing trials with $\mathrm{AX}+$ will, according to the comparator hypothesis, result in a decline in the conditioned response evoked by A relative to stimulus B. Simulations of the comparator hypothesis conducted with a wide range of parameter values have led to similar outputs. The only simulations that we have conducted that do not result in conditioned responding to $\mathrm{A}$ being less than to $\mathrm{B}$ are those that have the influence of the comparator process $(\mathrm{k} 2)$ set to zero. Under these circumstances, conditioned responding to $\mathrm{A}$ is predicted to equal that of $\mathrm{B}$.

A number of experiments have tested A after conditioning trials with $\mathrm{A}+$ and then $\mathrm{AX}+$. However, for a number of reasons, these studies do not allow us to draw any firm conclusions about whether this training undermines conditioned responding to A or leaves it unaffected. Mackintosh (1971) gave two groups of rats eight pairings of A with shock. AX was then paired with the same shock for 1 trial with one group and for 16 trials with the other
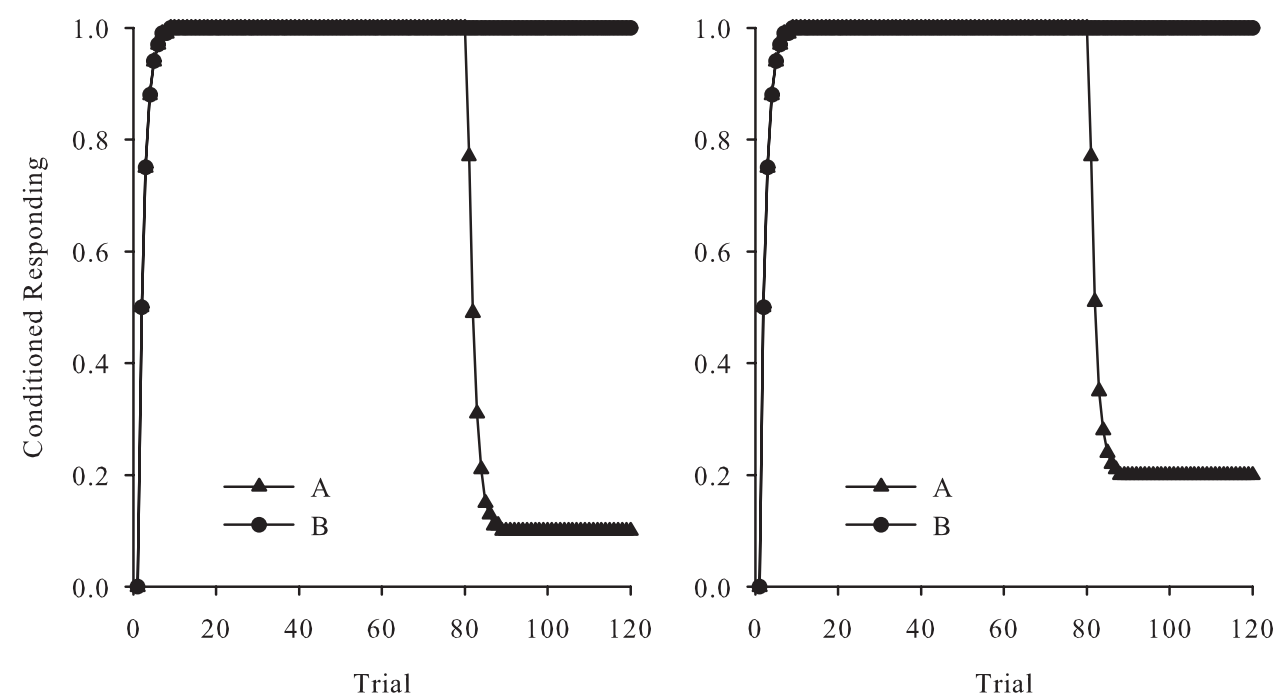

Figure 1. Simulated strengths of conditioned responding to A and to B according to the equations provided by Stout and Miller (2007). Left panel: Simulation in which A and B are first paired, in isolation, with the unconditioned stimulus (US) before AX and B are paired with the US. Right panel: Simulation in which A and $\mathrm{B}$ are first paired, in isolation, with the US before A, AX, and B are paired with the US. See text for further details. 
group. Test trials revealed a stronger conditioned response to A in the group that received 16 compound trials. Although this outcome is the opposite of that predicted by comparator theory, it is conceivable that conditioning with A had not reached asymptote by the end of the first stage of training and that the outcome of the experiment was because of the benefits of the repeated pairings of A with shock in the second stage.

An experiment reported by Pearce and Redhead (1999) also demonstrated that adding $\mathrm{X}$ to $\mathrm{A}$ can enhance responding to A. In their Experiment 1, two groups of rats were initially given training in which stimulus A was paired with a US. In Stage 2, the experimental group was given paired presentations of AX with a US, and the control group continued to receive paired presentations of A with a US. The results from the final test session revealed stronger conditioned responding to $\mathrm{A}$ in the experimental than in the control group, which is opposite that predicted by the comparator hypothesis. This result, however, does not necessarily trouble the comparator hypothesis. Pearce and Redhead changed the US between Stages 1 and 2 from sucrose solution to food pellets, and Blaisdell, Denniston, and Miller (1997) have argued in these circumstances that comparator effects will be less pronounced. These results must remain, therefore, at least provocative, but not decisive.

Rescorla (1999) reported an appetitive Pavlovian conditioning experiment in which rats initially received trials in which $\mathrm{A}$ and $\mathrm{B}$ were paired separately with food and then in Stage 2 a compound of $\mathrm{A}$ and $\mathrm{X}$ was paired with food. In a subsequent test session, there was no difference in the rate of responding to $\mathrm{A}$ and $\mathrm{B}$, a result that, at face value, seems to support the view of conditioning provided by the Rescorla-Wagner (1972) model. However, this result can be accommodated by the comparator hypothesis if it is assumed that conditioning with $\mathrm{A}$ and $\mathrm{B}$ did not reach asymptote in Stage 1. If this were the case, then the detrimental effects of adding the comparator, $\mathrm{X}$, in Stage 2 could have been countered exactly by the additional learning about A that takes place. This would result in conditioned responding to A and to B (which was not presented at all during Stage 2) being rather similar during the final test session, which is exactly what was observed.

In contrast to these results, an experiment by Arcediano, Escobar, and Miller (2004) appears to provide support for the comparator hypothesis. Rats were first given trials in which a stimulus, A, signaled shock. After this training, an experimental group received pairings of AX with shock, and a control group received pairings of BX with shock. In a final test session, A elicited more conditioned responding in the control group than in the experimental group, a result that is compatible with the predictions that can be derived from the comparator hypothesis but, at face value, not more standard associative models (e.g., Rescorla \& Wagner, 1972). However, this difference between the experimental and control groups does not necessarily imply that $\mathrm{AX}+$ training in the experimental group weakened the response to A. Instead, training with $\mathrm{BX}$ in the control group may have enhanced responding to A through generalization. At the outset of training in Stage 2, the associative strength of AX will be close to asymptote (blocking further conditioning to A), whereas the associative strength of BX will be rather low (enabling conditioning to B). It is plausible that the associative strength acquired by B during Stage 2 generalized to $\mathrm{A}$ at test and thereby enhanced its conditioned response.
In addition to the experiment by Arcediano et al. (2004), two other studies have reported that the ability of A to control responding is attenuated following $\mathrm{A}+/ \mathrm{AX}+$ training. One was conducted with rats (Hall, Mackintosh, Goodall, \& Dal Martello, 1977), the other with humans (Denton \& Kruschke, 2006). In both experiments, the salience of $\mathrm{X}$ was greater than that of A. As Hall et al. (1977) pointed out, it is conceivable that subjects paid more attention to $\mathrm{X}$ than to A during compound conditioning, even to the extent of failing to notice $\mathrm{A}$ on some trials. $\mathrm{X}$ would then gain considerable associative strength and weaken responding to $\mathrm{A}$, possibly through a process of overexpectation (Wagner \& Rescorla, 1972). Overall, therefore, there is scant unequivocal support for the prediction made by the comparator hypothesis that the blocking treatment $\mathrm{A}+/ \mathrm{AX}+$ will weaken responding to $\mathrm{A}$.

The purpose of the two experiments we report here was to examine the impact of conditioning with an AX compound, following prior conditioning of $\mathrm{A}$, on the conditioned response evoked by A. As we have described above, this training will, according to the comparator hypothesis (Miller \& Matzel, 1988), have a disruptive effect on the conditioned response evoked by A, whereas, according to the Rescorla-Wagner (1972) model, this training will have no effect on conditioned responding to A.

\section{Experiment 1}

In Stage 1 of the experiment, a single group of rats received appetitive Pavlovian conditioning in which two stimuli, A and B, were paired with food (see Table 1). In Stage 2, rats continued to receive pairings of $\mathrm{A}$ and $\mathrm{B}$ with food, and they also received trials in which a compound of $\mathrm{A}$ and $\mathrm{X}$ was paired with food. After this training, the rats were presented with test trials with $\mathrm{A}$ and $\mathrm{B}$, conducted in extinction. To encourage rats to differentiate between the experimental stimuli, we also included nonreinforced trials with $\mathrm{Y}$ in the first two stages of the experiment. The Rescorla and Wagner (1972) theory predicts that, provided conditioning with A has reached asymptote, the inclusion of trials with AX in Stage 2 will have no impact on conditioned responding to this stimulus. Therefore, the strength of responding to A should be equal to that of B. According to the comparator hypothesis, however (Miller \& Matzel, 1988), the introduction of trials with AX will provide A with an effective comparator stimulus, $\mathrm{X}$. Consequently, there should be a loss of conditioned responding to A, but not to B, during Stage 2, despite the fact that both of these stimuli are paired with food. Trials with A were intermixed with $\mathrm{AX}, \mathrm{B}$, and $\mathrm{Y}$ during Stage 2 in the experimental group to ensure that $\mathrm{A}$ and $\mathrm{B}$

Table 1

Design of Experiment 1

\begin{tabular}{clc}
\hline Stage 1 & Stage 2 & Test \\
\hline A+ & A+ & \\
B + & AX+ & A vs. B \\
Y- & B + & \\
\hline
\end{tabular}

Note. Rats were initially given paired presentations of A and B with food; $\mathrm{Y}$ was nonreinforced. This training continued in Stage 2 with the addition of paired presentations of $\mathrm{AX}$ with food. In a final test session, $\mathrm{A}$ and $\mathrm{B}$ were presented in isolation and in extinction. 
were both familiar as individual stimuli before the test. A simulation of this training with the comparator hypothesis is shown in the right panel of Figure 1. The parameters for this simulation were identical to those used in the simulation that is shown in the left panel of Figure 1; the only substantial change to the simulation is that there were an equal number of $\mathrm{A}+$ and $\mathrm{AX}+$ trials intermixed throughout Stage 2. For this simulation, there will be an influence of nonreinforcement because on $\mathrm{A}+$ trials the association between $\mathrm{A}$ and $\mathrm{X}$ will be weakened according to Equation 2. In keeping with assumptions made by Stout and Miller (2007), the value of the learning rate parameter for nonreinforcement $(\mathrm{k} 1)$ was set to 0.18 on these trials. Despite this increase in the complexity of the design, our simulation of the comparator hypothesis reveals that the strength of conditioned responding to A should still fall, and it should be noted that other simulations we have conducted reveal that this prediction remains true even when the value of $k 1$ is set to the maximum value of 1 .

\section{Method}

Subjects. The subjects were 32 experimentally naive male hooded Lister rats (Rattus norvegicus) supplied by Harlan Olac (Bicester, Oxon, England) that were maintained and tested at the School of Psychology, Cardiff University (Cardiff, Wales). Before the start of the experiment, at an age of approximately 3 months, they were gradually reduced to $80 \%$ of their free-feeding weights. They were maintained at these weights throughout the experiment by being fed a restricted amount after each experimental session. The rats were housed in pairs in a light-proof room in which the lights were on for $14.5 \mathrm{hr} /$ day. They were tested at the same time on successive days during the period when the lights were on in their holding room.

Apparatus. All experimental procedures were performed in eight identically specified operant boxes supplied by Campden Instruments Ltd. (Loughborough, England). The boxes were individually housed in light- and sound-attenuated chambers that were ventilated by an exhaust fan that provided a background noise level of $67 \mathrm{~dB}$ (scale A). Each box had three aluminum walls and an aluminum ceiling; a transparent plastic door served as the fourth wall. The floor was made of stainless steel rods. The internal dimensions of a box were $24.5 \mathrm{~cm}$ wide $\times 23.0 \mathrm{~cm}$ deep $\times 21.0$ $\mathrm{cm}$ high. The boxes were equipped with a concave, recessed magazine to which 45-mg food pellets could be delivered (Formula P, P. J. Noyes, Lancaster, NH). The tray was covered by a sprung, transparent plastic flap ( $6 \mathrm{~cm}$ high $\times 5 \mathrm{~cm}$ wide). Pushing this flap actuated a microswitch that was recorded as a response. Each box had a single $2.8-\mathrm{W}$ lamp covered by $1.5-\mathrm{cm}$ diameter plastic disk located on the roof of the magazine. Loudspeakers located in the ceiling could be used to present broadband white noise, a $4-\mathrm{Hz}$ train of clicks and a $100-\mathrm{Hz}$ buzz. All auditory stimuli were approximately $10 \mathrm{~dB}$ (scale A) above the background noise level. A Risc PC microcomputer (Acorn Computers Ltd., Cambridge, England), which was programmed in Arachnid (Paul Fray Ltd., Cambridge, England), was used to control the experimental events and record responses.

Procedure. Rats were first trained to retrieve pellets from the food tray. In each of two sessions, pellets were delivered to the tray on a 1-min, fixed-time schedule. In the first session, the flaps that covered the food tray were held open with masking tape; in the second session, and for the remainder of the experiment, the flap was not held open.

During Stage 1, there were 10 sessions in which A and B were paired with food and $\mathrm{Y}$ was not. In each session, there were eight trials with A, eight with B, and four with Y. Each of these stimuli was presented for $10 \mathrm{~s}$, and after trials with $\mathrm{A}$ and $\mathrm{B}$, a single food pellet was delivered into the magazine. There were no programmed consequences after trials with $\mathrm{Y}$. The mean intertrial interval (ITI), defined as the duration between the termination of one trial and the onset of the next, was $3 \mathrm{~min}$ (range $=2-4 \mathrm{~min}$ ). The stimuli that served as A and B were counterbalanced as the onset of the magazine light and white noise. The stimulus that served as $\mathrm{X}$ was counterbalanced with $\mathrm{Y}$ as either a buzz or a train of clicks. The trial sequence was random with the constraint that no more than two trials of the same type could occur in succession. The first trial within a session began $60 \mathrm{~s}$ after subjects were placed into the conditioning chambers, and subjects were removed $60 \mathrm{~s}$ after the termination of the final trial. The duration of each session for this stage was $62 \mathrm{~min}, 20 \mathrm{~s}$.

During Stage 2, there were eight sessions in which A, B, and AX were paired with food and $\mathrm{Y}$ was not. In each session, there were 5 presentations each of $\mathrm{Y}, \mathrm{A}$, and $\mathrm{AX}$. To equate the number of times that $\mathrm{A}$ and $\mathrm{B}$ were each paired with food, there were 10 presentations of $\mathrm{B}$ in each session. After trials with $\mathrm{A}, \mathrm{B}$, and $\mathrm{AX}$, a single food pellet was delivered into the magazine; there were, once again, no programmed consequences after trials with $\mathrm{Y}$. The details of the ITI and trial sequencing were the same as in Stage 1. The duration of the session in this stage was $77 \mathrm{~min}, 20 \mathrm{~s}$.

For the final test session, A, AX, and $\mathrm{Y}$ were each presented once and $\mathrm{B}$ was presented twice. Food was presented after trials with $\mathrm{A}, \mathrm{AX}$, and $\mathrm{B}$, but not after Y. After these trials there were 10 nonreinforced trials each with A and with B. The details of the ITI and trial sequencing were the same as in Stage 1. A record was taken of the amount of time that each rat pushed back the Perspex flap in front of the food magazine on each trial. These values were used to calculate durations of magazine activity, which were regarded as the measure of conditioning.

\section{Results and Discussion}

The results of the training from Stage 1 are shown on the left-hand side of Figure 2. Conditioning proceeded smoothly, and very quickly there was a clear discrimination between $\mathrm{A}$ and $\mathrm{Y}$ and between B and Y. This observation was confirmed by a two-way analysis of variance (ANOVA) of individual mean durations of magazine activity to $\mathrm{A}, \mathrm{B}$, and $\mathrm{Y}$ with the factors of stimulus (A, $\mathrm{B}$, and $\mathrm{Y}$ ) and session (1 to 10). This analysis revealed an effect of stimulus, $F(2,62)=43.85$; an effect of session, $F(9,279)=6.96$; and an interaction between these factors, $F(18,558)=7.02$. Simple effects analysis revealed an effect of stimulus on each session, $F s(2,620)>4.33$, and paired $t$ tests, corrected according to the Bonferroni procedure, revealed that responding to $\mathrm{A}$ and $\mathrm{B}$ was higher than to $\mathrm{Y}$ on each session. No further comparisons were significant. For these and all subsequent statistical tests, we adopted a significance level of .05 .

The results of the training from Stage 2 are shown in the right-hand side of Figure 2. The discrimination between the stimuli that were reinforced $(\mathrm{A}, \mathrm{B}$, and $\mathrm{AX})$ and nonreinforced $(\mathrm{Y})$ was evident throughout this stage, and adding $\mathrm{X}$ to $\mathrm{A}$ resulted in a 


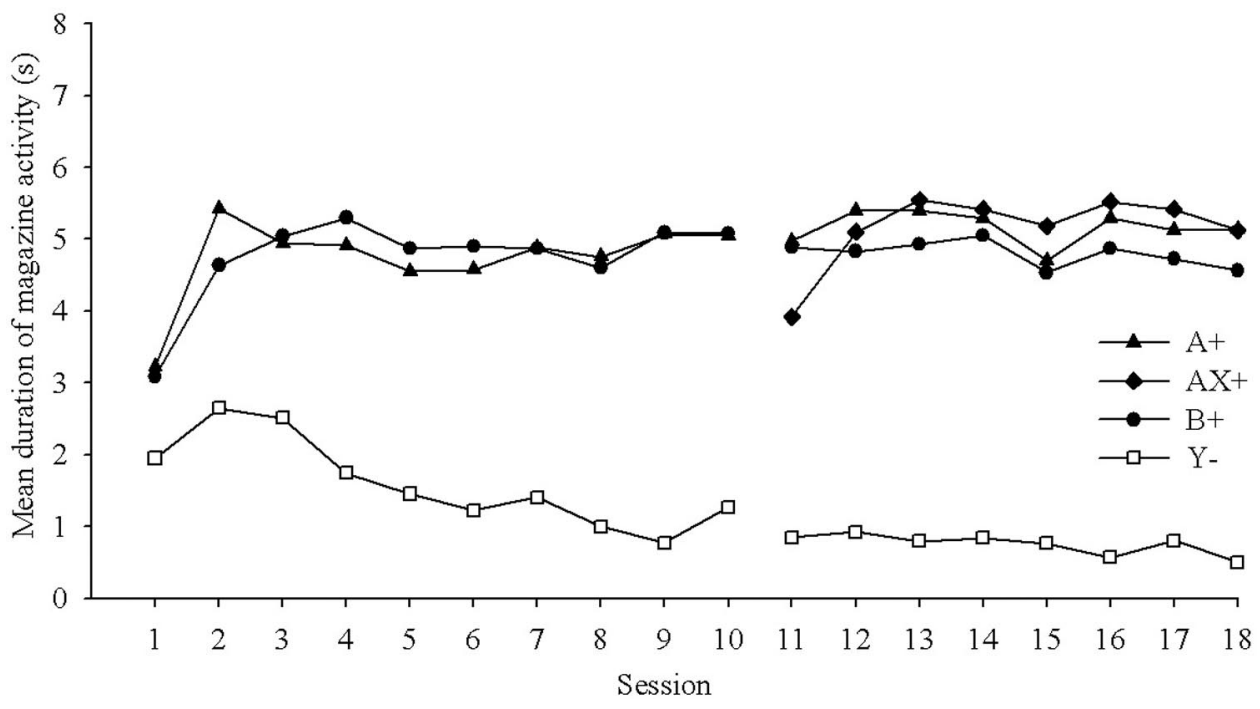

Figure 2. The mean durations of magazine activity to A, B, and Y during the 10 sessions of training in Stage 1 and to $\mathrm{A}, \mathrm{AX}, \mathrm{B}$, and $\mathrm{Y}$ during the 8 sessions of training in Stage 2 of Experiment 1.

slight disruption of conditioned responding during Session 11. Furthermore, there was a small difference between A and B. A two-way ANOVA of individual mean durations of magazine activity for the eight sessions with the factors of CS and session revealed an effect of session, $F(7,217)=2.46$; an effect of CS, $F(3,93)=89.51$; and a Session $\times$ CS interaction, $F(21,651)=$ 3.35. Analysis of simple main effects revealed significant effects of $\mathrm{CS}$ on each session, $F_{\mathrm{S}}(3,744)>50.66$. Paired $t$ tests, again corrected according to the Bonferroni procedure, revealed that responding to $\mathrm{A}, \mathrm{B}$, and $\mathrm{AX}$ was higher than to $\mathrm{Y}$ on each session. In addition, responding to $\mathrm{AX}$ was significantly weaker than to $\mathrm{A}$ on Session 1. No further comparison was significant.

The results of the final test session, in which A and B were presented in isolation and nonreinforced, are shown, in two-trial blocks, in Figure 3. The numerical difference between A and B that was seen in Stage 2 persisted during the test session and was, if anything, enhanced. This observation was confirmed with a two-way ANOVA of individual mean duration scores with the factors of CS and trial block that revealed an effect of CS, $F(1$, $31)=4.26$, confirming that responding to A was stronger than to $\mathrm{B}$, and an effect of trial block, $F(4,124)=44.20$. The $\mathrm{CS} \times$ Trial Block interaction was not significant, $F(4,124)=2.01$.

The results from the test trials reveal that training in which both A and AX were paired with food did not weaken responding during A. Indeed, the fact that magazine activity was more frequent during the trials with $\mathrm{A}$ than during those with $\mathrm{B}$ indicates that the conditioning trials with $\mathrm{AX}$ enhanced responding to $\mathrm{A}$. This outcome is opposite to that predicted by the comparator hypothesis (Miller \& Matzel, 1988).

\section{Experiment 2}

The prediction from the comparator hypothesis that $\mathrm{A}+/ \mathrm{AX}+$ trials will weaken responding to $\mathrm{A}$ is based on the assumption that $\mathrm{X}$ will gain at least some associative strength as a result of this training. Presenting A by itself will then activate a memory of $\mathrm{X}$ and its relationship with the US that, by virtue of the comparator process, will then reduce the capacity of A to elicit a response. There was, however, no attempt to measure the associative strength of $X$ in Experiment 1, and the experiment may have failed to lend support to the comparator hypothesis because $\mathrm{X}$ was associatively neutral at the time that $\mathrm{A}$ was tested. If this was the

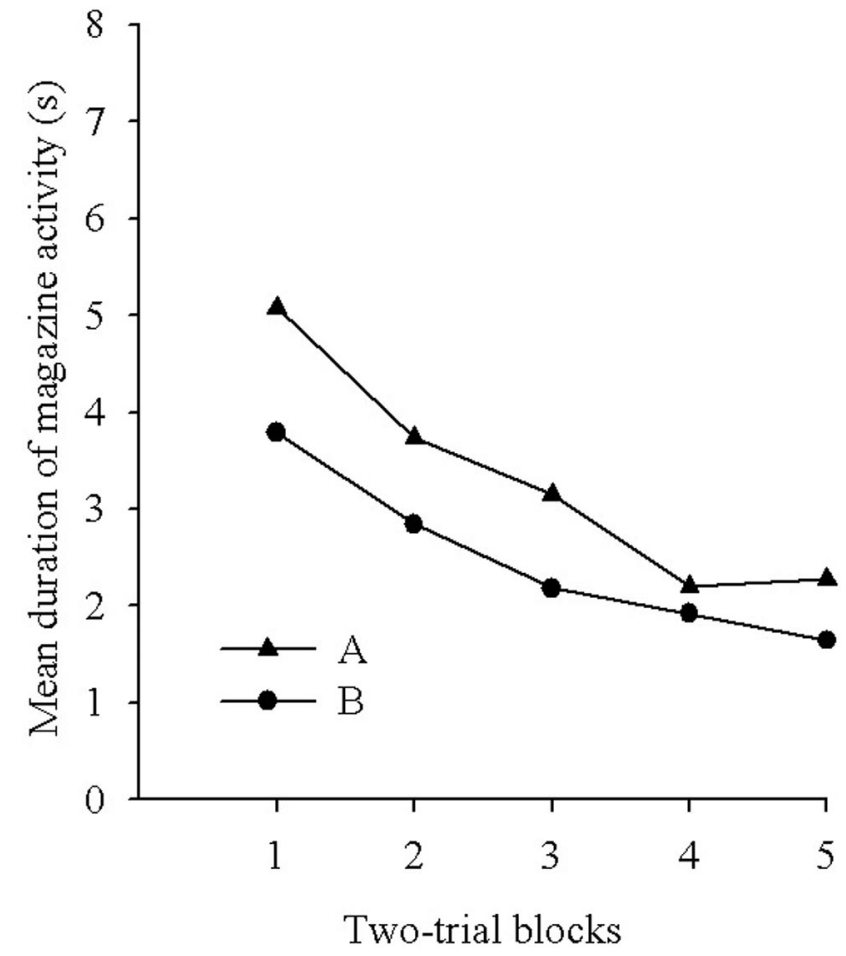

Figure 3. The mean durations of magazine activity to A and to B, shown in two-trial blocks, during the test stage of Experiment 1. 
case, then the experiment would not have provided a fair test of the hypothesis. Of course, there would then be the problem, for the comparator hypothesis, of explaining why $\mathrm{X}$ failed to gain any associative strength despite being repeatedly paired with food. To provide a more thorough test of the comparator hypothesis, therefore, the first two stages of Experiment 2 were the same as Experiment 1, but before the test trials with $\mathrm{A}$ and $\mathrm{B}$, we conducted tests to determine whether the $\mathrm{A}+/ \mathrm{AX}+$ treatment resulted in effective conditioning with $\mathrm{X}$ (see Table 2). After Stage 2, the rats were divided into two groups. Group $\mathrm{X}$ received nonreinforced trials with $\mathrm{X}$, and Group $\mathrm{Y}$ received nonreinforced trials with $\mathrm{Y}$, which had never been paired with food. If the $\mathrm{A}+/ \mathrm{AX}+$ trials result in $\mathrm{X}$ acquiring associative strength, then responding during the test trials with $\mathrm{X}$ will be stronger than with $\mathrm{Y}$.

On the assumption that responding to $\mathrm{X}$ would be stronger than to $\mathrm{Y}$, a further purpose of the experiment was to examine the impact of repeated nonreinforced exposure to $\mathrm{X}$ on responding to A. We have already noted that as a result of the $\mathrm{AX}+$ trials in Stage 2, comparator theory predicts that responding to A will be reduced as $\mathrm{X}$ gains in associative strength. Conversely, the hypothesis predicts that as $\mathrm{X}$ loses associative strength during the extinction trials in Stage 3, the opportunity will be provided for A to elicit a progressively stronger response than if it were presented by itself (cf. Kaufman \& Bolles, 1981; Matzel, Schachtman, \& Miller, 1985). We tested this prediction after the completion of Stage 3 by giving both groups a series of test trials with A and B. The extinction trials with $\mathrm{Y}$ can be expected to leave the associative properties of $\mathrm{X}$ relatively unaffected in Group $\mathrm{Y}$, and on the basis of the results from Experiment 1, responding is expected to be stronger to $\mathrm{A}$ than to $\mathrm{B}$. If the prediction just drawn from the comparator hypothesis is correct, then the extinction trials with $\mathrm{X}$ will result in stronger responding to $A$ in Group $X$ than in Group Y.

We also use the proposed experiment to evaluate an explanation for the results of Experiment 1 that has hitherto been ignored. Granted that $\mathrm{X}$ acquires a measure of associative strength during the $\mathrm{A}+/ \mathrm{AX}+$ training, it is also possible that this treatment will result in $\mathrm{A}$ and $\mathrm{X}$ entering into within-compound associations with each other (e.g., Rescorla, 1980). The presentation of A by itself for the test trials in that experiment would then excite the representation of $X$, which in turn would activate the representation of the US. This indirect activation of the US representation, combined with the activation through its direct association with $\mathrm{A}$, would then result in a supernormal response to $\mathrm{A}$ and in superior

Table 2

Design of Experiment 2

\begin{tabular}{cccc}
\hline Stage 1 & Stage 2 & Stage 3 & Test \\
\hline $\mathrm{A}+$ & $\mathrm{A}+$ & & \\
$\mathrm{B}+$ & $\mathrm{AX}+$ & $\mathrm{X}-$ & A vs. B \\
& $\mathrm{B}+$ & $\mathrm{Y}-$ & \\
$\mathrm{Y}-$ & $\mathrm{Y}-$ & & \\
\hline
\end{tabular}

Note. Rats were initially given paired presentations of A and B with food; $\mathrm{Y}$ was nonreinforced. This training continued in Stage 2, with the addition of paired presentations of AX with food. In Stage 3, rats in Group X were given nonreinforced trials with $\mathrm{X}$, and rats in Group $\mathrm{Y}$ were given nonreinforced trials with Y. responding to $\mathrm{A}$ than to $\mathrm{B}$. In the case of Group $\mathrm{X}$ in this experiment, the extinction trials with $\mathrm{X}$ will mean that when $\mathrm{A}$ is presented for testing, it will no longer be able to activate indirectly the representation of the US, and the response to A should be no different than that to $\mathrm{B}$.

\section{Method}

Subjects and apparatus. The subjects were 32 experimentally naive male hooded Lister rats that were maintained in an identical fashion to the subjects in Experiment 1. The apparatus was the same as in Experiment 1.

Procedure. Stages 1 and 2 of Experiment 2 were identical in all respects to Stages 1 and 2 of Experiment 1. Thus, rats first received 10 sessions in which $\mathrm{A}$ and $\mathrm{B}$ were paired with food and $\mathrm{Y}$ was not. There were subsequently 8 sessions in which $\mathrm{A}, \mathrm{B}$, and AX were each paired with food and $\mathrm{Y}$ was again nonreinforced.

After this training, the rats were split into two groups and given two sessions of extinction with either $\mathrm{X}$ or $\mathrm{Y}$. For the first of these sessions, the first 5 trials consisted of 2 training trials with $\mathrm{B}+$ and 1 with each of $\mathrm{A}+, \mathrm{AX}+$, and $\mathrm{Y}-$. Group $\mathrm{X}$ then received 16 nonreinforced trials with $\mathrm{X}$, and Group $\mathrm{Y}$ received 16 trials with $\mathrm{Y}$. On the following day, subjects in Groups $\mathrm{X}$ and $\mathrm{Y}$ received 20 nonreinforced trials with $\mathrm{X}$ and $\mathrm{Y}$, respectively.

For the final test session all rats received 10 trials each with $\mathrm{A}$ and $\mathrm{B}$. The details of this session were identical to the final test session of Experiment 1, except that no warm-up trials preceded the trials with A and B. Any procedural details omitted from this experiment were the same as for Experiment 1.

\section{Results and Discussion}

The results of the training from Stage 1 are shown in the left-hand side of Figure 4. Conditioning proceeded in a similar fashion to Experiment 1, and very quickly there was, again, a clear discrimination between $\mathrm{A}$ and $\mathrm{Y}$ and between $\mathrm{B}$ and $\mathrm{Y}$. This observation was confirmed by a one-way ANOVA of individual mean durations of magazine activity with the factors of stimulus (A, B, and $\mathrm{Y}$ ) and session (1 to 10). This analysis revealed an effect of stimulus, $F(2,62)=80.11$; an effect of session, $F(9$, $270)=7.45$; and an interaction between these factors, $F(18$, $558)=13.23$. Simple effects analysis revealed an effect of stimulus on each session, $F_{\mathrm{S}}(2,620)>11.98$, and paired $t$ tests corrected according to the Bonferroni procedure revealed that the duration of magazine activity was greater for $\mathrm{A}$ and $\mathrm{B}$ than $\mathrm{Y}$ on each session, but there were no differences between A and B.

The results of the training from Stage 2 are shown in the right-hand side of Figure 4. In keeping with the results of Experiment 1 , the discrimination between the stimuli that were reinforced (A, B, and AX) and nonreinforced (Y) was evident throughout this stage, and adding $\mathrm{X}$ to $\mathrm{A}$ resulted in a slight disruption of conditioned responding during Session 11. A two-way ANOVA of individual mean durations of magazine activity with the factors of CS and session revealed an effect of CS, $F(3,93)=203.00$, but no effect of session $(F<1)$. There was, however, a significant Session $\times$ CS interaction, $F(21,651)=5.57$. Analysis of simple main effects revealed a significant effect of CS on each session, $F \mathrm{~s}(3,744)>86.91$. Paired $t$ tests, again corrected according to the Bonferroni procedure, revealed that responding to $\mathrm{A}, \mathrm{B}$, and $\mathrm{AX}$ 


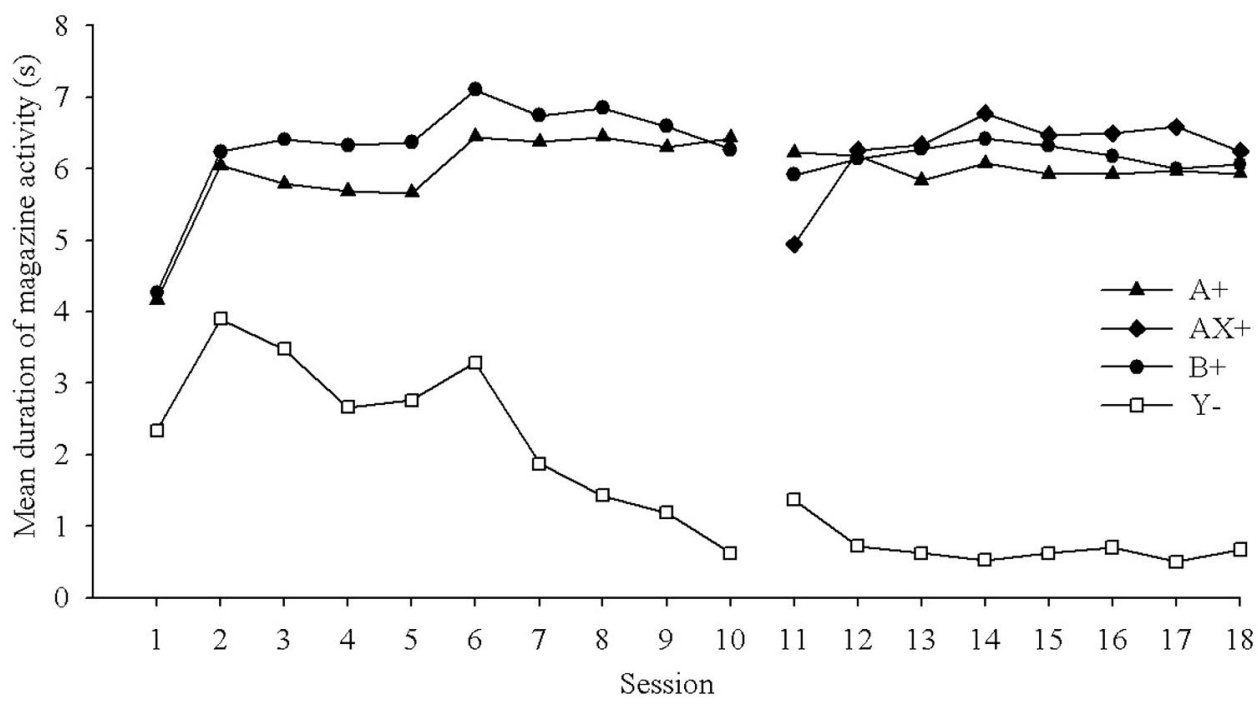

Figure 4. The mean durations of magazine activity to A, B, and Y during the 10 sessions of training in Stage 1 and to $\mathrm{A}, \mathrm{AX}, \mathrm{B}$, and $\mathrm{Y}$ during the 8 sessions of training in Stage 2 of Experiment 2.

was higher than to $\mathrm{Y}$ on each session and, in addition, that responding to $\mathrm{AX}$ was significantly weaker than to $\mathrm{A}$ in Session 11. No further comparisons were significant.

The results of Stage 3, in which $\mathrm{X}$ and $\mathrm{Y}$ were nonreinforced for, respectively, Group X and Group Y, are shown in two-trial blocks in the top panel of Figure 5. The mean duration of magazine activity to $\mathrm{X}$ in Group $\mathrm{X}$ was, at first, greater than the mean duration of magazine activity to $\mathrm{Y}$ in Group $\mathrm{Y}$, suggesting that $\mathrm{X}$ did acquire an association with the US in Stage 2. However, the effects of nonreinforcement eventually resulted in a reduction in responding to $\mathrm{X}$, so that by the end of this stage, the mean durations of magazine activity to $\mathrm{X}$ and $\mathrm{Y}$ were at a similar low level. We confirmed these observations with a two-way ANOVA of individual mean durations of magazine activity with the factors of group (X vs. Y) and two-trial block, which revealed significant effects of group, $F(1,30)=13.67$; session, $F(17,510)=6.26$; and a significant Group $\times$ Session interaction, $F(17,510)=3.92$. Analysis of simple main effects revealed an effect of trial block for Group X, $F(17,510)=9.44$, but not for Group Y $(F<1)$, confirming the detrimental effects of nonreinforcement on $\mathrm{X}$ for Group X. Furthermore, conditioned responding to $\mathrm{X}$ in Group $\mathrm{X}$ was stronger than to $\mathrm{Y}$ in Group $\mathrm{Y}$ on Trial Blocks 1 to $5, F \mathrm{~s}(1$, $540)>5.93$, but not on any of the remaining trial blocks, $F \mathrm{~s}(1$, $540)<2.42$.

The results of the final stage in which test trials with A and B were given to both Groups $\mathrm{X}$ and $\mathrm{Y}$ are shown, respectively, in the lower left- and lower right-hand panels of Figure 5. The results from Group Y reveal that the mean durations of magazine activity to A were greater than to $\mathrm{B}$, a result that replicates the results of Experiment 1. However, this difference was abolished in Group X. With the exception of the first two-trial block, there was no indication of any difference in the mean durations of magazine activity to A and B. We confirmed these observations by means of a three-way ANOVA of individual mean durations of magazine activity with the factors of group (Group X vs. Group Y), CS (A vs. B), and two-trial block, which revealed a significant three-way interaction, $F(4,120)=2.60$. Simple main effects analysis of this interaction revealed a significant $\mathrm{CS} \times$ Trial Block interaction for Group Y but not for Group X. Further simple effects analysis revealed that, crucially, responding to $\mathrm{A}$ was higher than to $\mathrm{B}$ on Trial Blocks 2 and 3 for Group Y, $F \mathrm{~s}(1,150)>5.53$, but not on Trial Blocks 1, 4, and 5, and on none of the trial blocks for Group $\mathrm{X}, F_{\mathrm{s}}(1,150)<3.29$. Other results from the simple effects analysis revealed a Group $\times$ CS interaction on Trial Block 2, F(1, $150)=3.90$, and a Group $\times$ CS interaction that just missed significance on Trial Block 3, $F(1,150)=3.79, p=.054$. Further simple effects analysis of the interaction on Trial Block 3 revealed a difference between Groups $\mathrm{X}$ and $\mathrm{Y}$ in their conditioned responding to $\mathrm{A}, F(1,300)=5.36$, but not to $\mathrm{B}(F<1)$. This final result is of interest because it implies that the extinction trials with $\mathrm{X}$ in Group $\mathrm{X}$ weakened responding to A. Other results from the overall ANOVA were an effect of trial block, $F(4,120)=65.58$, and a Trial Block $\times$ CS interaction, $F(4,120)=2.64$. None of the remaining effects or interactions were significant, $F_{\mathrm{s}}(1,30)<2.26$ and $F(4,120)<1$, respectively.

The results failed to confirm the predictions from the comparator hypothesis that were made in the introduction to this experiment. Thus, there was no evidence that responding to $\mathrm{A}$ was reduced as a result of pairing it with $\mathrm{X}$ during the $\mathrm{A}+/ \mathrm{AX}+$ trials of Stage 2, nor was there any evidence that responding to A was enhanced as a result of subsequently presenting $\mathrm{X}$ by itself for extinction. Indeed, the test results for Group Y revealed the opposite of the first of these outcomes, and a comparison of the test results with A for the two groups revealed the opposite of the second.

A straightforward explanation for all of the results in Experiment 2 can be based on the assumption that the conditioning trials with $\mathrm{AX}+$ in Stage 2 resulted in the growth of a within-compound association between A and X (e.g., Rescorla, 1980). The test trials with $\mathrm{A}$ in Group $\mathrm{Y}$ would then activate the representation of $\mathrm{X}$, which in turn would activate the representation of the US and enhance the conditioned response to A relative to $\mathrm{B}$. The extinction 

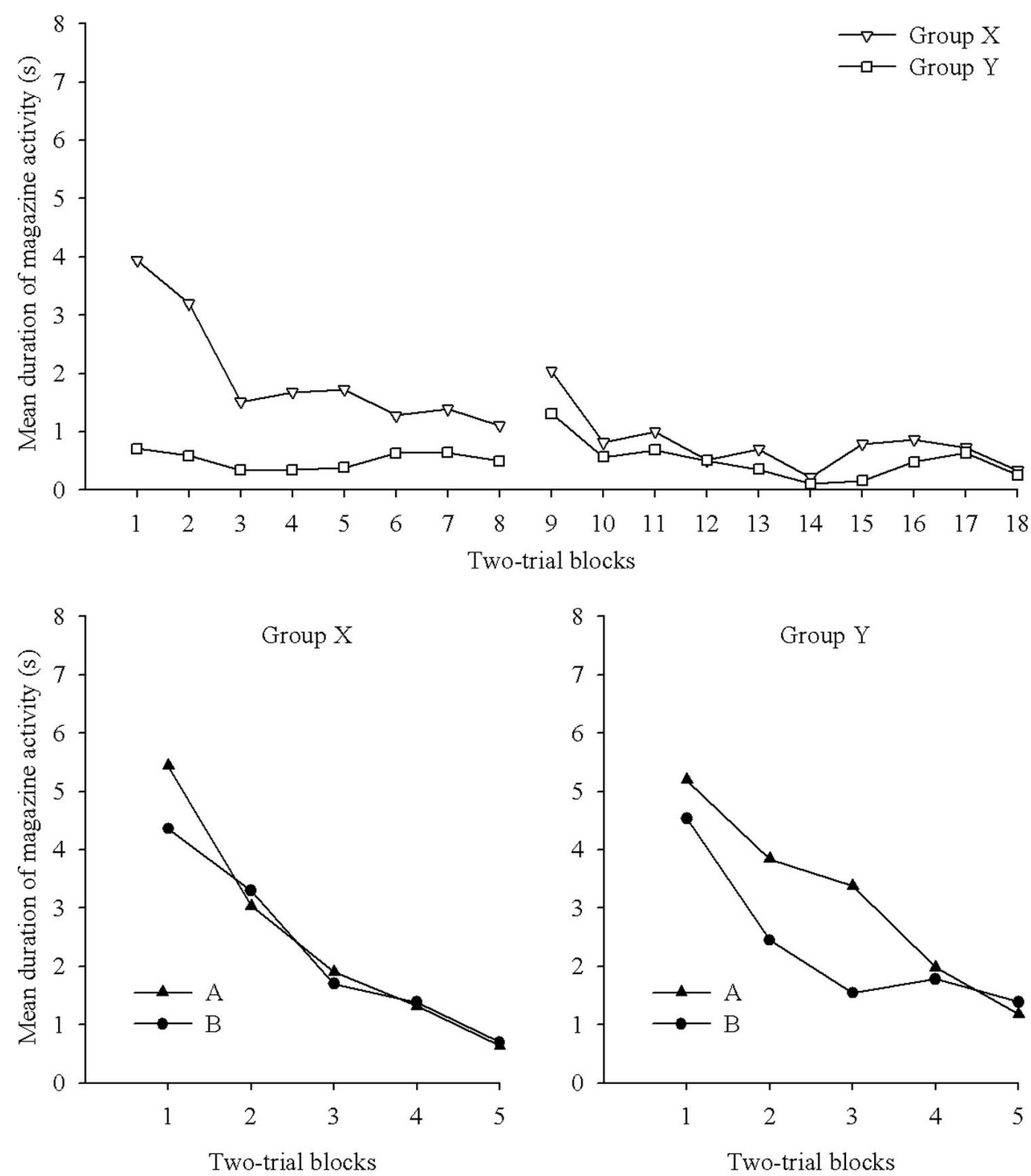

Figure 5. The mean durations of magazine activity to $\mathrm{X}$ and to $\mathrm{Y}$ in, respectively, Groups $\mathrm{X}$ and $\mathrm{Y}$ during the two sessions of extinction in Stage 3 of Experiment 2 (top panel), and the mean durations of magazine activity to A and to B, shown in two-trial blocks, for Group Y (bottom-left panel) and Group X (bottom-right panel) during the test stage of Experiment 2.

trials with X, after Stage 2, would mean that when A was presented for testing in Group X, it would no longer be able to activate the US representation through the indirect route mediated by $\mathrm{X}$, and responding to A will be the same as to B.

A possible objection to the foregoing analysis can be based on the fact that during Stage 3, Group X, but not Group Y, received extinction trials with a stimulus that had previously been paired with food. It might be argued, therefore, that extinction with any stimulus, not just one paired with A, would have produced a similar outcome to the experiment. Fortunately, this possibility can be called into question because it fails to explain why extinguishing $X$ in Group $X$ selectively reduced responding to A, but not to B. An appeal to a general effect of extinction on responding would predict that performance to B would also be reduced in Group X, yet there was no indication of a difference between Group $\mathrm{X}$ and Group $\mathrm{Y}$ in the strength of responding to B.

\section{General Discussion}

Throughout this article, we have argued that the reported results are difficult to explain in terms of the comparator hypothesis (Miller \& Matzel, 1988). In essence, this theory assumes that responding to a target stimulus will be weakened by pairing it with another stimulus - a comparator stimulus - that has associative strength. Moreover, the greater the associative strength of the comparator stimulus, the weaker the response to the target stimulus. On the whole, our results contradicted these proposals. Both 
experiments showed that responding to a target stimulus was enhanced rather than weakened by pairing it with another stimulus.

We now consider whether a more sophisticated version of the comparator hypothesis can explain our findings. Denniston, Savastano, and Miller (2001) put forward what they call the extended comparator hypothesis (see Savastano, Arcediano, Stout, \& Miller, 2003, and Stout \& Miller, 2007, for formal versions of this hypothesis). This hypothesis again assumes that responding to a target stimulus can be weakened if it is paired with a comparator stimulus (through a so-called first-order comparator process), but the influence of the comparator stimulus will be affected to the extent that it is itself paired with another comparator stimulus (through a second-order comparator process). In the case of our experiments, higher order comparator processes become important only if the context, $\mathrm{C}$, is assumed to enter into associations with the US and with the other experimental stimuli. Stout and Miller (2007) have assumed that associations are unidirectional, which will lead to a total of 12 associations that need to be considered: A-C, A-X, A-US, B-C, B-US, C-A, C-B, C-X, C-US, X-A, $\mathrm{X}-\mathrm{C}$, and $\mathrm{X}-\mathrm{US}$. To appreciate how these associations affect first-order comparator processes concerning the target association A-US, consider rows 1a to 1e of Table 3. Thus far, we have assumed the strength of the response elicited by A will be determined by the strength of the A-US association, minus a value determined by the product of the $\mathrm{A}-\mathrm{X}$ and the $\mathrm{X}-\mathrm{US}$ associations (row 1a, first order column, Table 3 ) multiplied by the parameter k2 (see Equation 2). Once the presence of the context is acknowledged, then responding to A will be further weakened by a firstorder comparator process, which will be based on the A-C and C-US associations (row 1c, first order column, Table 3). The subtractive effects of each process will then sum together to determine the overall disruptive effect on responding to A.

Turning now to second-order comparator processes, these weaken the influence of first-order comparators in the same way that first-order comparators weaken the influence of a target CS. By way of example, if the impact of the first-order comparator term in row 1a of Table 3 is being calculated, it must be borne in

Table 3

The Associations That Will Be Involved in the First-, Second-, and Third-Order Comparator Processes That Might Influence Responding to Target Stimuli $A$ and $B$ as a Result of Training With $A+, B+, A X+$ in Context $C$.

\begin{tabular}{cccc}
\hline $\begin{array}{c}\text { Target } \\
\text { association }\end{array}$ & 1st order & 2nd order & 3rd order \\
\hline A-US & & & \\
$1 \mathrm{a}$ & $\mathrm{A}-\mathrm{X} \times \mathrm{X}-\mathrm{US}$ & $\mathrm{A}-\mathrm{C} \times \mathrm{C}-\mathrm{X}$ & $\mathrm{N} / \mathrm{A}$ \\
$1 \mathrm{~b}$ & & $\mathrm{X}-\mathrm{C} \times \mathrm{C}-\mathrm{US}$ & $\mathrm{C}-\mathrm{B} \times \mathrm{B}-\mathrm{US}$ \\
$1 \mathrm{c}$ & $\mathrm{A}-\mathrm{C} \times \mathrm{C}-\mathrm{US}$ & $\mathrm{A}-\mathrm{X} \times \mathrm{X}-\mathrm{C}$ & $\mathrm{N} / \mathrm{A}$ \\
$1 \mathrm{~d}$ & & $\mathrm{C}-\mathrm{X} \times \mathrm{X}-\mathrm{US}$ & $\mathrm{N} / \mathrm{A}$ \\
$1 \mathrm{e}$ & & $\mathrm{C}-\mathrm{B} \times \mathrm{B}-\mathrm{US}$ & $\mathrm{N} / \mathrm{A}$ \\
$\mathrm{B}-\mathrm{US}$ & & & \\
$2 \mathrm{a}$ & $\mathrm{B}-\mathrm{C} \times \mathrm{C}-\mathrm{US}$ & $\mathrm{C}-\mathrm{X} \times \mathrm{X}-\mathrm{US}$ & $\mathrm{C}-\mathrm{A} \times \mathrm{A}-\mathrm{X}$ \\
$2 \mathrm{~b}$ & & & $\mathrm{X}-\mathrm{A} \times \mathrm{A}-\mathrm{US}$ \\
$2 \mathrm{c}$ & & $\mathrm{C}-\mathrm{A} \times \mathrm{A}-\mathrm{US}$ & $\mathrm{C}-\mathrm{X} \times \mathrm{X}-\mathrm{A}$ \\
$2 \mathrm{~d}$ & & & $\mathrm{~A}-\mathrm{X} \times \mathrm{X}-\mathrm{US}$ \\
\hline
\end{tabular}

Note. $\quad$ US $=$ unconditioned stimulus; N/A $=$ not applicable. mind that when $\mathrm{A}$ activates the representation of $\mathrm{X}, \mathrm{X}$ will activate a representation of the context, which will activate a representation of the US (row 1b, second order column). This second-order activation of the US will weaken the first-order activation of the US by an amount determined by the product of the $\mathrm{X}-\mathrm{C}$ and $\mathrm{C}-\mathrm{US}$ associations multiplied by $\mathrm{k} 2$. The response to $\mathrm{A}$ will thus be stronger than if the second-order comparator process did not take place. The five second-order comparator terms in rows 1a to 1e of Table 3 will all weaken the negative impact on responding of the two first-order comparator stimuli for A. The remaining rows in the first- and second-order comparator columns of Table 3 show the associations that will determine the strength of responding to $\mathrm{B}$ as a result of first- and second-order comparator processes.

It is not easy to predict informally the outcome of second-order comparator processes for Experiments 1 and 2, but it is clear that this outcome will be affected by two factors relating to the context. The first is the salience of the context. Associations involving the context are more likely to influence the predicted outcome of the experiments when the salience of the context is high rather than low, relative to the other stimuli. The second factor is the amount of exposure to the context between successive trials. Associations $\mathrm{C}-\mathrm{A}, \mathrm{C}-\mathrm{B}$, and $\mathrm{C}-\mathrm{X}$ are likely to be weakened through exposure to the context by itself, and the more they are weakened, the less influence they have on the outcome of the second-order comparator processes.

We conducted a set of computer simulations, based on Equations $1 \mathrm{a}, 1 \mathrm{~b}$, and 2 , but they included second-order comparators. In addition, we systematically manipulated both the strength of the associations involving the context and the relative salience of the context. We achieved the former by allowing the ITI to permit only a single cycle of extinction with the context (massed trials) or, for each interval, to permit 18 cycles of extinction with the context (distributed trials). The latter was achieved by setting the salience of $\mathrm{A}, \mathrm{B}$, and $\mathrm{X}$ at .11, .35, and .71 for the low-, medium-, and high-salience conditions, respectively, whereas the salience of the context was always . 35 . The salience of the US was always .71 , and the value of $\lambda$ was 1.0. The value of $k 2$ was .9. The value of the extinction parameter, $\mathrm{k} 1$ (the learning rate parameter for nonreinforced trials; see Equation 1b), was .18. When two first-order comparator stimuli could influence the response to the target CS, or when two second-order comparator stimuli could influence the impact of a first-order comparator stimulus (rows 1a to 1e of Table 3 ), then the influence of the two comparator stimuli was determined by the sum of their individual effects (providing the sum never exceeded 1). These principles and parameter values were taken from the sometimes-competing retrieval model described by Stout and Miller (2007).

The results from the simulations are shown in Figure 6, which depicts the predicted strength of responding to $\mathrm{A}$ and to $\mathrm{B}$ during 80 cycles of Stage 1 training $(\mathrm{A}+/ \mathrm{B}+)$ and a further 40 cycles of Stage 2 training $(\mathrm{A}+/ \mathrm{B}+/ \mathrm{AX}+)$. The order in which each trial was simulated was block randomized, and each panel represents the mean of 10 simulations. As anticipated, manipulating both the context salience and the effects of extinction during the ITI had an effect on the predicted outcome of the experiments. Even so, for all but one of the parameter values that were selected, there was no occasion on which responding to $\mathrm{A}$ is predicted to be stronger than responding to $\mathrm{B}$ as a result of the Stage 2 treatment. For the simulation shown in the middle panel of the right-hand column of 
Distributed trials

Salience of $\mathrm{A} / \mathrm{B} / \mathrm{X}=0.11$

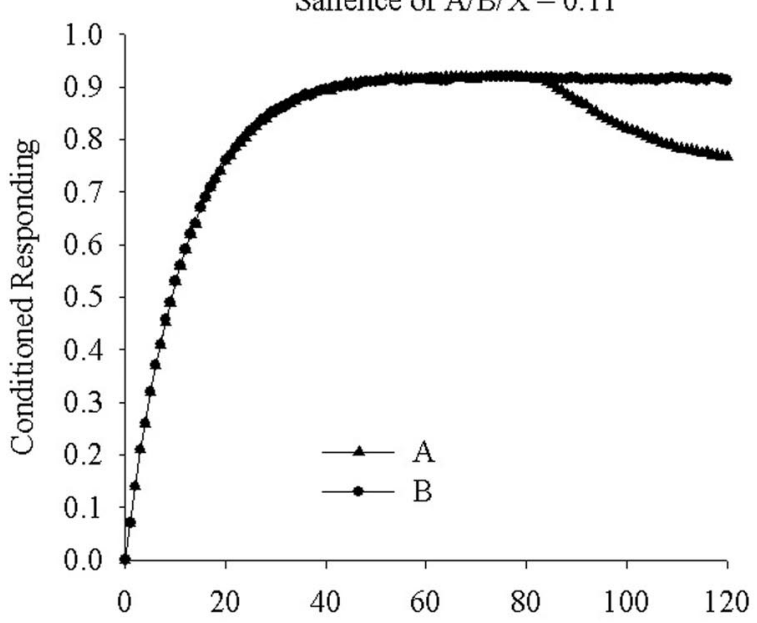

Salience of $\mathrm{A} / \mathrm{B} / \mathrm{X}=0.35$

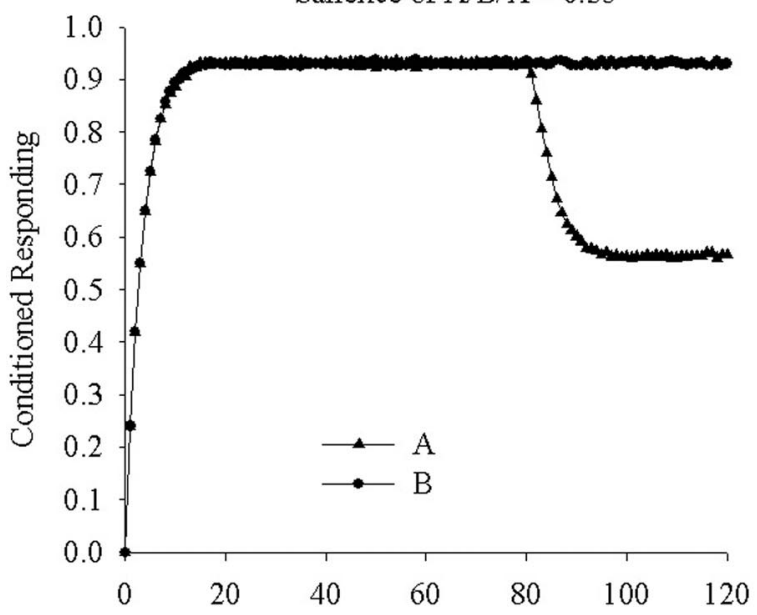

Salience of $\mathrm{A} / \mathrm{B} / \mathrm{X}=0.71$

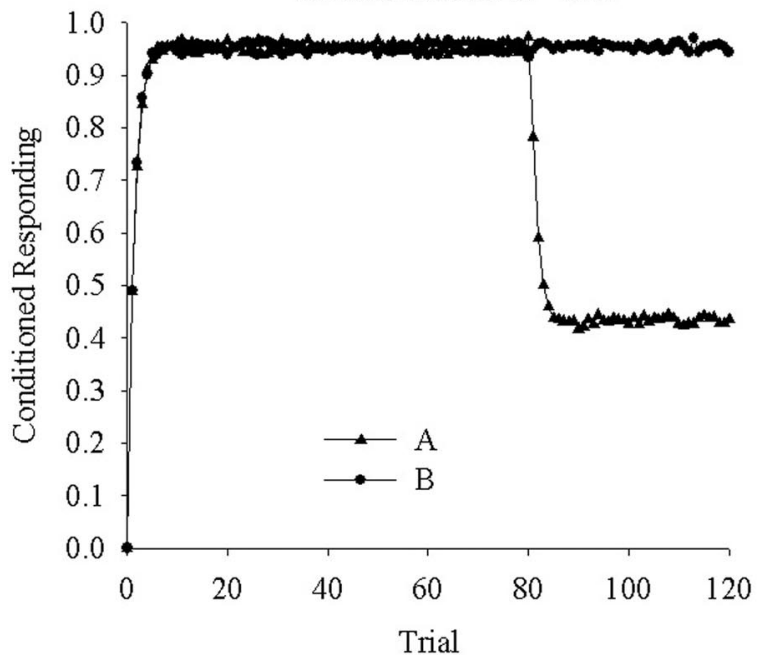

Massed trials

Salience of $\mathrm{A} / \mathrm{B} / \mathrm{X}=0.11$

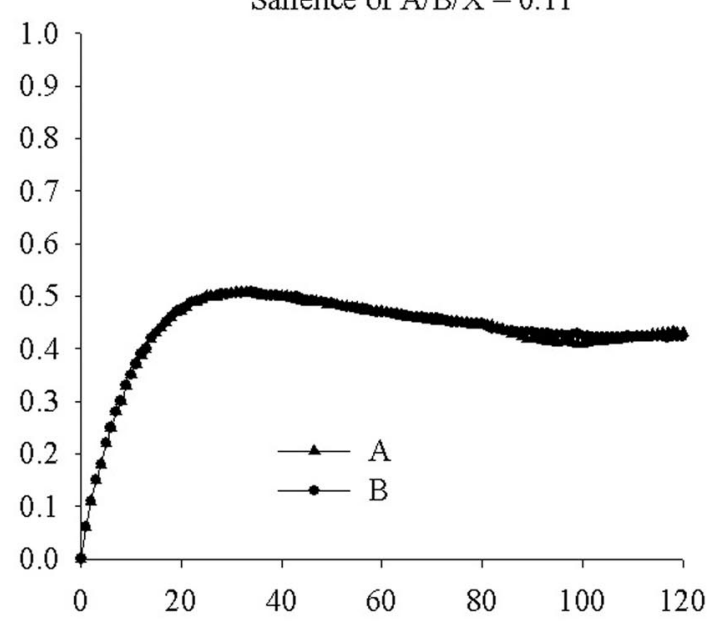

Salience of $\mathrm{A} / \mathrm{B} / \mathrm{X}=0.35$

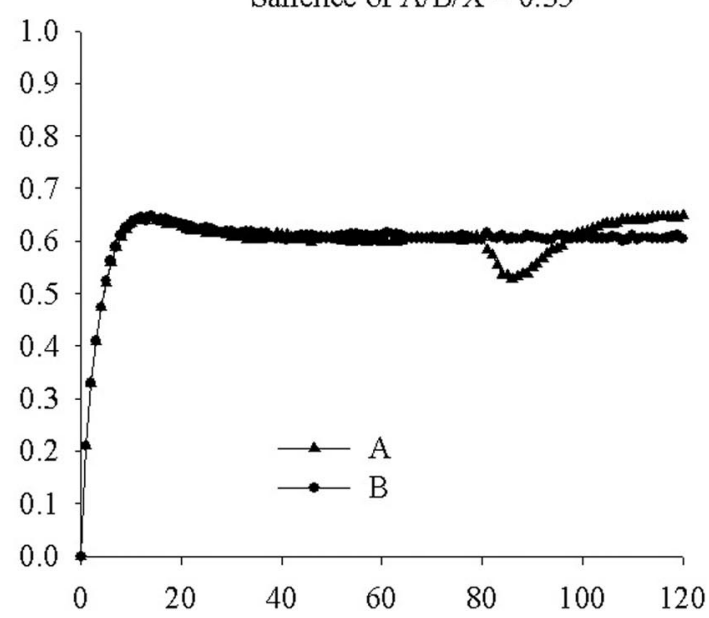

Salience of $\mathrm{A} / \mathrm{B} / \mathrm{X}=0.71$

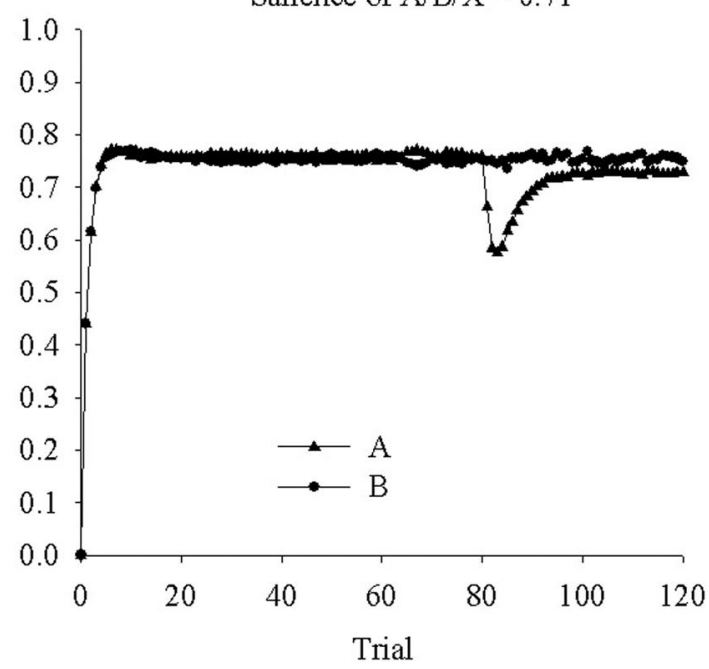


Figure 6, there is a period, after an initial predicted drop in responding to $\mathrm{A}$ relative to $\mathrm{B}$, in which performance to $\mathrm{A}$ is predicted to be slightly stronger than to B. Under these circumstances, the salience of the context was as great as the CS there was and only one cycle of nonreinforcement of the context between successive trials.

The comparator process can be taken a step further with associations contributing to a third-order comparator process that will reduce the effectiveness of second-order comparator stimuli. The associations that may serve this function for our experimental designs are listed in the right-most column of Table 3. For example, the product of the two associations identified in the right-most column of Row $1 b$ will reduce the second-order influence of the associations in the column to the left. If there are no more than three cycles of nonreinforcement of the context during each interval between successive trials, then by appealing to third-order comparator processes it is possible for the comparator hypothesis to predict that our training will result in stronger responding to A than B (R. R. Miller, personal communication, October 2008).

Thus, our findings can be explained by the comparator hypothesis, but only with a selection of parameter values that will lead to the prediction that the training will result in a strong context-food association. To test this prediction, we examined magazine activity during 10-s periods before each trial during Stage 2 of Experiment 1. The mean duration of this activity was $0.5 \mathrm{~s}$, which is no different than that recorded during the nonreinforced trials with $\mathrm{Y}$, $0.5 \mathrm{~s}$, and considerably lower than that recorded during the reinforced trials, $5.07 \mathrm{~s}$. On the basis of this evidence, it appears that as a result of the training we adopted, the contextual associations were relatively weak. Furthermore, simulating the current experiments successfully (with either second- or third-order comparisons) under the assumption that there were no more than three cycles of nonreinforcement of the context between successive trials is far removed from the reality of the experimental design. The intertrial interval was, on average, 18 times longer than the duration of the CSs; this ratio is equivalent to the ratio of trials to cycles of contextual nonreinforcement that was used in the simulations of the sometimes-competing retrieval model shown in the left-hand panels of Figure 6. Thus, it is only in circumstances that were unlikely to have prevailed in our experiments that the comparator hypothesis is able to explain our findings. In addition, with the parameters that are necessary for the sometimes-competing retrieval model to predict the present results - that is, under circumstances in which the context becomes highly associated with the US - the theory also predicts that blocking should no longer be observed. Although the current experiments do not allow us to conclude whether blocking was present or not, experiments conducted in our laboratory, with an ITI similar to that in the current experiments, have demonstrated blocking (Dopson, Pearce \& Haselgrove, 2009).
The present results also pose a problem for the theory of conditioning proposed by Rescorla and Wagner (1972). According to this theory, if the associative strength of A has reached asymptote during the course of $\mathrm{A}+/ \mathrm{AX}+$ training, then the associative strength of $\mathrm{X}$ will be zero. The results from the extinction trials in Stage 3 of Experiment 2 showed, to the contrary, that $\mathrm{X}$ retained a considerable measure of associative strength after the conditioning trials. One response to this result is to suggest that conditioning with A had not reached asymptote by the time we conducted the test trials with X. Another response is to look to other theories of conditioning, for example, Pearce (1994) or Wagner (2003), which do not predict that the effects of blocking will be complete as a result of $\mathrm{A}+/ \mathrm{AX}+$ training. On the basis of the available evidence, it is not possible to choose between these alternatives.

Van Hamme and Wasserman (1994; see also Dickinson \& Burke, 1996) proposed a modification to the Rescorla-Wagner (1972) theory that allows it to explain so-called retrospective revaluation effects. They suggested that after conditioning with $\mathrm{AX}+$, say, nonreinforced trials with $\mathrm{X}$ will activate a representation of $\mathrm{A}$, and because of the absence of $\mathrm{A}$ its salience will be negative. Substituting this negative salience into the equation proposed by Rescorla and Wagner then leads to the prediction that the nonreinforced trial with $X$ will result in an increase in the associative strength of A. Of course, the opposite outcome was observed in Experiment 2, which poses a challenge to these modified versions of the Rescorla-Wagner theory.

The experiments reported here are not the first to indicate that within-compound associations develop during blocking. In a conditioned flavor-aversion experiment reported by Speers, Gillan, and Rescorla (1980), rats first received paired presentations of flavors A and B with illness and then in Stage 2 compounds of AX and BY, both of which were again paired with illness. To examine whether a within-compound association had developed between A and $\mathrm{X}$ and between $\mathrm{B}$ and $\mathrm{Y}, \mathrm{A}$ was first paired with illness, and $\mathrm{B}$ was not; a choice test was then given between $\mathrm{X}$ and $\mathrm{Y}$, which revealed a stronger aversion to $\mathrm{X}$ than to $\mathrm{Y}$. These results are clearly compatible with the results of Experiment 1 and, in particular, with those of Experiment 2. Where the current experiments are novel, however, is in demonstrating that a within-compound association can facilitate the conditioned response evoked by the blocking stimulus. After $\mathrm{A}+/ \mathrm{AX}+$ training, we found that responding to $\mathrm{A}$ was more vigorous than responding to $\mathrm{B}$, which had consistently been paired with food by itself. If the strength of responding to $\mathrm{B}$ is taken as an indication of the strength of the response normally elicited by $\mathrm{A}$, then the test results indicate that the $\mathrm{A}+/ \mathrm{AX}+$ trials resulted in a greater than normal level of responding to this stimulus. To our knowledge, this is the first occasion on which such an effect has been shown. An effect related to that described by Speers et al. (1980) has been reported by Batsell and Batson (1999; see also Batson \& Batsell, 2000, and

Figure 6 (opposite). Simulated strengths of conditioned responding to A and to B according to the equations provided by Stout and Miller (2007). The left column shows simulations assuming distributed training trials, the right column shows simulations assuming massed training trials. The top, center, and bottom rows show simulations of training in which the salience of $\mathrm{A}, \mathrm{B}$, and $\mathrm{X}$ were less than, equal to, or higher than that of the context, respectively. See text for further details. 
Batsell, Paschall, Gleason \& Batson, 2001). Batsell et al. (1999) gave one group of rats pairings of odor A with illness in Stage 1 and then in Stage 2 trials in which a compound of odor A and taste $\mathrm{X}$ was paired with illness. The aversion conditioned to taste $\mathrm{X}$ was more substantial in this group than in a control group who only received Stage 2 training. The difference between the effect reported by Batsell and Batson and the experiments reported here is, of course, that the enhancement of responding in the current experiments was observed to a stimulus that had already been conditioned (A), whereas in the experiments reported by Batsell and Batson, the enhancement was observed to a stimulus that had not undergone such a treatment $(\mathrm{X})$.

The experiments reported here revealed the opposite pattern of results to the experiment described by Arcediano et al. (2004). It is difficult to be certain, without further research, why this discrepancy arose. There are a number of procedural differences between the methods used by Arcediano et al. and ourselves, and it is conceivable that one (or more) of these variables contributed to the difference observed between the experiments. Most notably, in the current experiments we used a within-subjects, appetitive conditioning procedure over many days of training, whereas Arcediano et al. used a between-subjects, aversive conditioning design over fewer days of training. It is also the case that the interval between successive trials in the experiment by Arcediano et al. had a mean of $14 \mathrm{~min}$, whereas in our experiments this mean was 3 min. Again, it is conceivable that this difference was responsible for the discrepancy between our and Arcediano et al.'s results. It is worth reiterating that the generalization of associative strength from B to A may provide an explanation for Arcediano et al.'s results. This explanation gains credibility when one appreciates that all of the stimuli used in their experiment were drawn from the same auditory modality.

A fundamental prediction of the theory proposed by Miller and his colleagues (e.g., Miller \& Matzel, 1988) is that conditioned responding to a target cue will be weakened by the addition of another cue, even when the US is presented on both of these types of trial. We could find no evidence to support this prediction in two appetitive Pavlovian conditioning experiments. To the contrary, our results indicated the opposite effect. These results are best understood if it is accepted that the effects on performance of retrieving stimulus representations are principally additive rather than subtractive.

\section{References}

Arcediano, F., Escobar, M., \& Miller, R. R. (2004). Is stimulus competition an acquisition deficit or a performance deficit? Psychonomic Bulletin \& Review, 11, 1105-1110.

Batsell, W. R., \& Batson, J. D. (1999). Augmentation of taste conditioning by a preconditioned odor. Journal of Experimental Psychology: Animal Behavior Processes, 25, 374-388.

Batsell, W. R., Paschall, G. Y., Gleason, D. I., \& Batson, J. D. (2001). Taste preconditioning augments odor-aversion learning. Journal of Experimental Psychology: Animal Behavior Processes, 27, 30-47.

Batson, J. D., \& Batsell, W. R. (2000). Augmentation, not blocking, in an $\mathrm{A}+/ \mathrm{AX}+$ flavor-conditioning procedure. Psychonomic Bulletin \& Review, 7, 466-471.

Blaisdell, A. P., Denniston, J. C., \& Miller, R. R. (1997). Unblocking with qualitative change in unconditioned stimulus. Learning and Motivation, $28,268-279$.
Blaser, R. E., Couvillon, P. A., \& Bitterman, M. E. (2004). Backward blocking in honeybees. Quarterly Journal of Experimental Psychology: Journal of Comparative and Physiological Psychology, 57(B), 349-360.

Denniston, J. C., Savastano, H. I., \& Miller, R. R. (2001). The extended comparator hypothesis: Learning by contiguity, responding by relative strength. In R. R. Mowrer \& S. B. Klein (Eds.), Handbook of contemporary learning (pp. 65-117). Mahwah, NJ: Erlbaum.

Denton, S. E., \& Kruschke, J. K. (2006). Attention and salience in associative blocking. Learning \& Behavior, 34, 285-304.

Dickson, A., \& Barke, J. (1996). Within-compound associations mediate the retrospective revaluation of casuality judgements. Quarterly Journal of Experimental Psychology, 49B 60-80.

Dickinson, A., Shanks, D. R., \& Evenden, J. L. (1984). Judgement of act-outcome contingency: The role of selective attribution. Quarterly Journal of Experimental Psychology: Human Experimental Psychology, 36(A), 29-50.

Dopson, J., Pearce, J. M., \& Haselgrove, M. (2009). Failure of retrospective revaluation to influence blocking. Journal of Experimental Psychology: Animal Behavior Processes.

Ganesan, R., \& Pearce, J. M. (1988). Effect of changing the unconditioned stimulus on appetitive blocking. Journal of Experimental Psychology: Animal Behavior Processes, 14, 280-291.

Hall, G., Mackintosh, N. J., Goodall, G., \& Dal Martello, M. (1977). Loss of control by a less valid or by a less salient stimulus compounded with a better predictor of reinforcement. Learning and Motivation, 8, 145158.

Hebb, D. O. (1949). The organisation of behavior. New York: Wiley.

Holland, P. C. (1984). Unblocking in Pavlovian appetitive conditioning. Journal of Experimental Psychology: Animal Behavior Processes, 10, 476-497.

Kamin, L. J. (1968). "Attention-like" processes in classical conditioning. In M. R. Jones (Ed.), Miami Symposium on the Prediction of Behavior: Aversive stimulation (pp. 9-31). Coral Gables, FL: University of Miami Press.

Kamin, L. J. (1969). Selective association and conditioning. In N. J. Mackintosh \& W. K. Honig (Eds.), Fundamental issues in associative learning (pp. 42-64). Halifax, Nova Scotia, Canada: Dalhousie University Press.

Kaufman, M. A., \& Bolles, R. C. (1981). A nonassociative aspect of overshadowing. Bulletin of the Psychonomic Society, 18, 318-320.

Le Pelley, M. E., Oakeshott, S. M., \& McLaren, I. P. L. (2005). Blocking and unblocking in human causal learning. Journal of Experimental Psychology: Animal Behavior Processes, 31, 56-70.

Mackintosh, N. J. (1971). An analysis of overshadowing and blocking. Quarterly Journal of Experimental Psychology, 23, 118-125.

Matzel, L. D., Schachtman, T. R., \& Miller, R. R. (1985). Recovery of an overshadowed association achieved by extinction of the overshadowing stimulus. Learning and Motivation, 16, 398-412.

Miller, R. R., \& Matzel, L. D. (1988). The comparator hypothesis: A response rule for the expression of associations. In G. H. Bower (Ed.), The psychology of learning and motivation (Vol. 22, pp. 51-92). San Diego, CA: Academic Press.

Pearce, J. M. (1994). Similarity and discrimination: A selective review and a connectionist model. Psychological Review, 101, 587-607.

Pearce, J. M., Graham, M., Good, M. A., Jones, P. M., \& McGregor, A. (2006). Potentiation, overshadowing and blocking of spatial learning based on the shape of the environment. Journal of Experimental Psychology: Animal Behavior Processes, 32, 201-214.

Pearce, J. M., \& Redhead, E. S. (1999). Enhanced Pavlovian conditioning with a change in appetitive reinforcer. Animal Learning \& Behavior, 27, 369-378.

Rescorla, R. A. (1980). Pavlovian second-order conditioning: Studies in associative learning. Hillsdale, NJ: Erlbaum.

Rescorla, R. A. (1999). Associative changes in elements and compounds 
when the other is reinforced. Journal of Experimental Psychology: Animal Behavior Processes, 25, 247-255.

Rescorla, R. A., \& Wagner, A. R. (1972). A theory of Pavlovian conditioning: Variations in the effectiveness of reinforcement and nonreinforcement. In A. H. Black \& W. K. Prokasy (Eds.), Classical conditioning II (pp. 64-99). New York: Appleton-Century-Crofts.

Rodrigo, T., Chamizo, V. D., McLaren, I. P. L., \& Mackintosh, N. J. (1997). Blocking in the spatial domain. Journal of Experimental Psychology: Animal Behavior Processes, 23, 110-118.

Savastano, H. I., Arcediano, F., Stout, S. C., \& Miller, R. R. (2003). Interaction between preexposure and overshadowing: Further analysis of the extended comparator hypothesis. Quarterly Journal of Experimental Psychology: Journal of Comparative and Physiological Psychology, 56B, 371-395.

Speers, M. A., Gillan, D. J., \& Rescorla, R. A. (1980). Within-compound associations in a variety of compound conditioning procedures. Learning and Motivation, 11, 135-149.

Stout, S. C., \& Miller, R. R. (2007). Sometimes-competing retrieval (SOCR): A formalization of the comparator hypothesis. Psychological Review, 114, 759-783.

Tennant, W. A., \& Bitterman, M. E. (1975). Blocking and overshadowing in two species of fish. Journal of Experimental Psychology: Animal Behavior Processes, 1, 22-29.

Van Hamme, L. J., \& Wasserman, E. A. (1994). Cue competition in casuality judgements: The role of nonpresentation of compound stimulus elements. Learning and Motivation, 25, 127-151.

Wagner, A. (2003). Context-sensitive elemental theory. Quarterly Journal of Experimental Psychology: Journal of Comparative and Physiological Psychology, 56B, 7-29.

Wagner, A. R., \& Rescorla, R. A. (1972). Inhibition in Pavlovian conditioning: Applications of a theory. In R. A. Boakes \& M. S. Haliday (Eds.), Inhibition and learning (pp. 301-336). New York: Academic Press.

Willner, J. A. (1978). Blocking of a taste aversion by prior pairings of extroceptive stimuli with illness. Learning and Motivation, 9, 125140

Received July 21, 2006

Revision received November 28, 2008

Accepted November 28, 2008

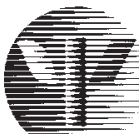

\section{American Psychological Association} Subscription Claims Information

Today's Date:

We provide this form to assist members, institutions, and nonmember individuals with any subscription problems. With the appropriate information we can begin a resolution. If you use the services of an agent, please do NOT duplicate claims through them and directly to us. PLEASE PRINT CLEARLY AND IN INK IF POSSIBLE.

PRINT FULL NAME OR KEY NAME OF INSTITUTION

\begin{tabular}{lll}
\hline ADDRESS & & \\
\hline CITY & STATE/COUNTRY & ZIP
\end{tabular}

YOUR NAME AND PHONE NUMBER

TITLE
MEMBER OR CUSTOMER NUMBER (MAY BE FOUND ON ANY PAST ISSUE LABEL)

$\overline{\text { DATE YOUR ORDER WAS MAILED (OR PHONED) }}$
_PREPAID $\quad$ CHECK $\frac{\text { CHECK/CARD CLEARED DATE: }}{}$

(If possible, send a copy, front and back, of your cancelled check to help us in our research of your clain.)

ISSUES: MISSING DAMAGED

VOLUME OR YEAR
NUMBER OR MONTH

Thank you. Once a claim is received and resolved, delivery of replacement issues routinely takes 4-6 weeks.

(TO BE FILLED OUT BY APA STAFF)

DATE RECEIVED:

ACTION TAKEN

STAFF NAME:
DATE OF ACTION:

INV. NO. \& DATE:

LABEL NO. \& DATE:

Send this form to APA Subscription Claims, 750 First Street, NE, Washington, DC 20002-4242

PLEASE DO NOT REMOVE. A PHOTOCOPY MAY BE USED. 